\title{
Fast, Very Fast, and Ultra-Fast Gas Chromatography-Mass Spectrometry of Thermally Labile Steroids, Carbamates, and Drugs in Supersonic Molecular Beams
}

\author{
Shai Dagan and Aviv Amirav \\ School of Chemistry, Sackler Faculty of Exact Sciences, Tel Aviv University, Ramat Aviv 69978, Tel Aviv, \\ Israel
}

\begin{abstract}
Gas chromatography-mass spectrometry (GC-MS) analyses of thermally labile compounds have been studied by using a short column fast gas chromatograph, coupled with fly-through electron ionization in supersonic molecular beams. Thirty-two compounds, which include steroids, carbamate pesticides, antibiotic drugs, and other pharmaceutical compounds, have been analyzed and the details of their GC-MS analysis are provided. The ability to analyze thermally labile compounds is discussed in relation to the speed of analysis. $A$ new term, "speed enhancement factor" (SEF), is defined as the product of column length reduction and the carrier gas linear velocity increase, as compared with normal GC-MS conditions. Fast, very fast, and ultra-fast GC-MS are defined with a SEF in the ranges of 5-30, 30-400, and 400-4000, respectively. Trade-offs in the degree of dissociation, speed, gas chromatograph resolution, and sensitivity were studied and examined with thermally labile molecules. The experimental factors that affect the dissociation are described with emphasis on its reduction. We claim that the use of supersonic molecular beams for sampling and ionization provides the ultimate capability in the GC-MS of thermally labile compounds. The obtained $70-\mathrm{eV}$ electron ionization mass spectra are shown, and an enhanced relative abundance of the molecular ion is demonstrated together with library search capability of these mass spectra, which is better than that reported with particle beam liquid chromatography-mass spectrometry. The performance of fast GC-MS in supersonic molecular beams is compared with other methods of fast GC-MS and with particle beam liquid chromatography-mass spectrometry. ( $\mathrm{Am}$ Soc Mass Spectrom 1996, 7, 737-752)
\end{abstract}

$\mathrm{G}$ as chromatography-mass spectrometry (GCMS) is the central technique employed today for the analysis of organic compounds, which includes analysis at trace levels in complex mixtures. However, GC-MS is limited in its scope and therefore is often replaced by liquid chromatography-mass spectrometry (LC-MS), although LC-MS analysis is more complicated to operate, exhibits poorer performance, and costs more.

The scope of conventional GC-MS is limited owing to two main reasons:

1. Relatively nonvolatile molecules (such as large polycyclic aromatic hydrocarbons) are incompatible with gas chromatography and especially incompatible with the mass spectrometer ion source. The ion source-limited temperature results in an early onset of chromatographic peak tailing.

Address reprint requests to Professor Aviv Amirav, School of Chemistry, Sackler Faculty of Exact Sciences, Tel Aviv University, Ramat Aviv, Tel Aviv 69978, Israel.
2. Many classes of compounds are thermally labile and decompose in the gas chromatograph (GC) or in the mass spectrometer ion source.

These two limitations are often interrelated. If a mixture contains both relatively nonvolatile compounds and thermally labile compounds, then at the temperatures required to handle the relatively nonvolatile compounds in the GC and ion source, the thermally labile molecules dissociate.

An obvious and known approach to further enhance the scope of GC-MS with thermally labile compounds is to use a short column for fast GC to reduce the residence time of the molecule in the separation column and thereby to minimize its dissociation [1-4]. Several methods of fast GC-MS have been developed, which include:

1. The "open split" method [5], which is perhaps the simplest method. It is based on the use of short columns with an unlimited column flow rate, connected through a $T$ flow splitter at $1 \mathrm{~atm}$ to a 
transfer line that leads into the mass spectrometer ion source with limited gas conductivity.

2. The "subambient" short column fast GC-MS [6, 7], which is based on sample injection at near atmospheric pressure into a short column, operated at subambient pressure through most of its length. In this method, a relatively high carrier gas linear velocity is obtained at a given total gas flow rate that is still acceptable by the GC-MS pumps.

3. A recently emerging approach is based on microbore short columns connected to time-of-flight mass spectrometry that is compatible in its scan speed with the narrow GC peak widths involved $[8,9]$.

All these fast GC-MS methods are based on the use of standard mass spectrometers with their conventional pumping capacity. Moreover, none of these methods addresses molecular and molecular ion dissociation in the mass spectrometer ion source, nor the ion source-related peak tailing (whose onset emerges earlier with the narrow peak widths associated with fast GC-MS).

Due to the difficulties with the GC-MS of relatively nonvolatile and especially thermally labile compounds, and to maintain the desirable feature of electron ionization fragment ion formation and library compatibility, the particle beam LC-MS method was developed $[10,11]$ and is widely used today [12-16]. This method is superior to GC-MS in terms of molecular transfer at the separation column, yet it suffers from the previously described ion source problems.

We have recently developed a new fast GC-MS approach based on the use of supersonic molecular beams (SMB) for sampling to and ionization in the mass spectrometer [4]. Our goal is to address all the problems and aspects that affect the GC-MS of thermally labile compounds, and thus to reach the upper capability limits in the GC-MS of thermally labile compounds. This will allow the achievement of the widest possible use of GC-MS, combined with the highest level of mass spectral information and total elimination of the mass spectrometer ion sourceinduced peak tailing [4].

The purpose of this article is to demonstrate and explain how the use of supersonic molecular beams [17] helps to minimize molecular dissociation at the GC injector, column, transfer line, and mass spectrometry ion source, as well as to achieve enhanced molecular weight mass spectral peaks combined with electron impact library searchable fragmentation patterns. We also will discuss what determines the upper limits of our ability in the analysis of thermally labile compounds with GC-MS.

\section{Experimental}

The experimental apparatus has been described partially before [4] and is shown schematically in Figure 1
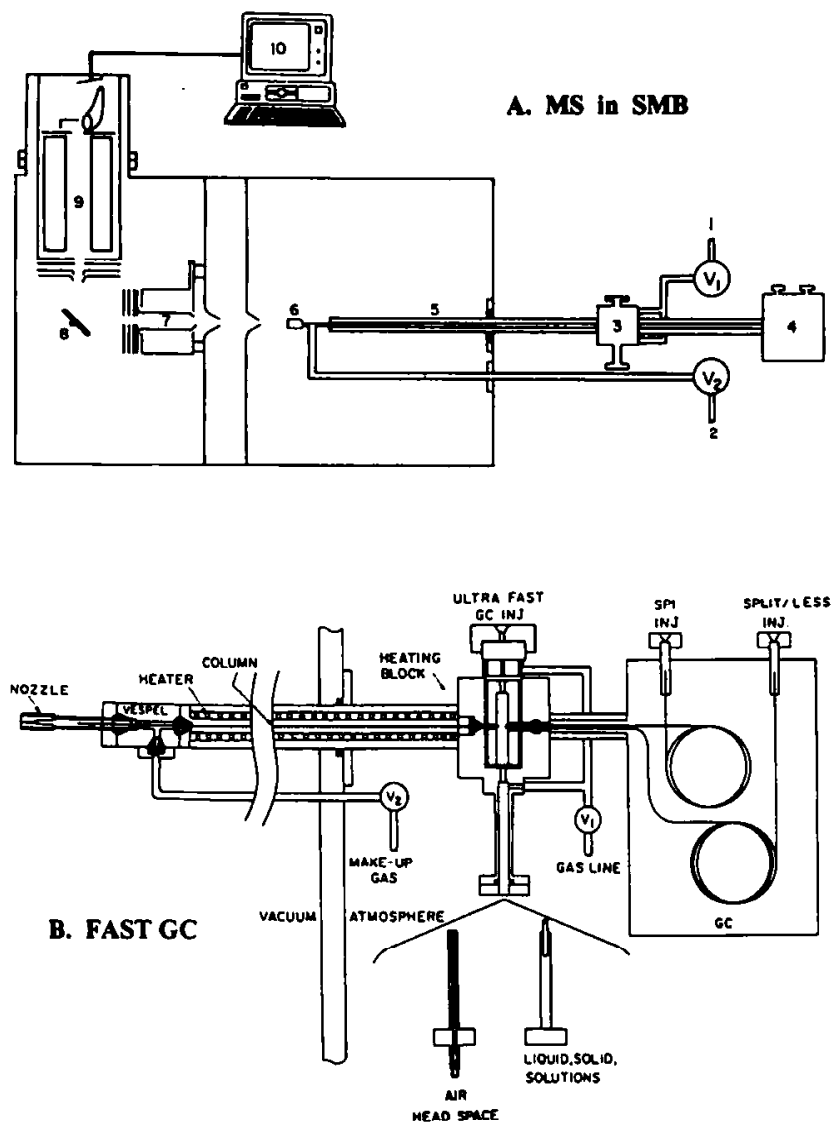

Figure 1. The fast GC-MS and the mass spectrometric apparatus. See text for details.

with emphasis on the fast GC inlet. In the upper portion (a), the sample is introduced either through a Varian (Walnut Creek, CA) 3400 GC (4) or through our homemade GC injector (3) and is transferred through a $50-\mathrm{cm}$-long megabore capillary column (5) to the supersonic nozzle (6).

The nozzle flow is supplied by both needle values $V_{1}$ and $V_{2}$. The supersonic beam (homemade) nozzle is an all ceramic or Vespel ${ }^{\circledR}$ nozzle which was heated separately. The carrier gas and sample molecules expand through the nozzle (6) into the first vacuum chamber and pass through the differentially pumped skimmer region before they enter the electron ionization source (7) in the high vacuum mass spectrometry chamber. The supersonic molecular beam is ionized by a fly-through, Brink-type [18], cylindrical electron ionization (EI) ion source (7), which allows free passage of the SMB. Typical emission currents were 5-20 mA, and a carburized thoriated tungsten filament was used [19]. The open Brink-type ion source is used because of its high ionization efficiency, which results from the relatively high emission current and multipass electron motion. We note that the nonuniform high ion source temperature is irrelevant to SMB mass spectrometry, because most of the molecules pass through the ion source, while the minority of molecules that scatter 
from its walls, thermalize and are undetected due to the background ion filtration method employed, as explained subsequently. The ions are extracted by the ion optics lens system attached to the EI ion source and are guided by a $90^{\circ}$ ion deflector (8) into a quadrupole mass analyzer (9) (VG-SXP 600, VG Quadrupole Ltd., Manchester, UK). The scanning rate of the quadrupole mass analyzer was typically $5-7 \mathrm{~Hz}$ (2000-2800 mass-to-charge ratio units per second).

Between the quadrupole mass analyzer and the channeltron ion detector, there is another ion optics element denoted "exit lens" that is a simple circular plate with a 3-mm hole. This plate was voltage biased externally to filter out ions produced from the thermal molecules of the vacuum background [17, 20,21]. This "background ion filtration," based on differences in ion energy between ions formed from beam species that have a high kinetic energy and vacuum background, enabled the selective transfer of ions produced in the hyperthermal SMB only. We emphasize that this method of background ion filtration is of vital importance to this work. In addition to elimination of the vacuum background-related noise, the backgrund-free EI ion source facilitates ultra-fast response time and exposes the mass spectra of vibrationally cold molecules. This finding is based on the fact that any molecule in the SMB that scattered from a surface, was thermalized, lost its directional kinetic energy, and thus was filtered out if it was ionized.

The $90^{\circ}$ ion deflector also can be moved upward on an XYZR vacuum manipulator and can be replaced by a suitable surface for hyperthermal surface ionization $[17,22]$ of the hyperthermal beam molecules. The work reported here was performed with EI only.

Figure 1b describes the fast GC inlet in detail. A commercial GC (Varian 3400) was used as a fast and very fast GC. The sample was injected from the split-splitless injector into a narrow bore column ( $4 \mathrm{~m} \times 0.25-\mathrm{mm}$ i.d.) to achieve fast GC. Alternatively, the sample was injected splitless "on column" from the septum-equipped temperature programmable injector (SPI) into a megabore column ( $3 \mathrm{~m} \times 0.53-\mathrm{mm}$ i.d.) to achieve very fast GC. The columns are transferred from the external GC to the homemade ultra-fast GC injector in a homemade transfer line whose temperature is controlled separately. Both columns can be interfaced simultaneously to the mass spectrometer through the ultra-fast GC injector and column.

The ultra-fast GC injector also can accept samples from a syringe inserted from its upper part. A homemade injector liner, made of Vespel, accepts the injected sample and vaporizes it directly into the $50-\mathrm{cm}$ long megabore capillary column that connects the injector and the supersonic nozzle. This capillary column serves for ultra-fast GC separation, and up to 0.1-0.2 $\mu \mathrm{L}$ of solution could be injected splitless. A second needle valve $V_{2}$ regulates a makeup gas flow rate and therefore the pressure behind the nozzle. Thus, needle valve $V_{2}$ also controls the carrier gas velocity in the ultra-fast GC column from $2000 \mathrm{~cm} / \mathrm{s}$ when it is closed, up to a protective reversed-flow direction.

\section{Results and Discussion}

\section{GC-MS Analysis of Underivatized Steroids and the Speed Enhancement Factor}

Steroids are a known class of molecules whose GC-MS requires attention. Usually the GC-MS of steroids is performed after their derivatization. However, a short column fast GC-MS of underivatized steroids was recently reported [1]. During the analysis of thermally labile steroids we realized that different steroids possess different degrees of thermolability. For instance, cholesterol is a relatively stable steroid whereas cortisone is a highly fragile compound. Thus, a different approach is required, dependent on the analyzed steroid.

The term "fast GC-MS" is commonly used in the literature. We found it to be loosely defined with regard to the speed of analysis, especially in terms of definition of the ability to analyze thermally labile compounds. We advance here a new, more quantitative term: speed enhancement factor (SEF). Conventional GC-MS is performed with a 30 -m-long narrow bore column that has a carrier gas flow rate of 1 $\mathrm{mL} / \mathrm{min}$, which corresponds to $34-\mathrm{cm} / \mathrm{s}$ helium linear velocity. The speed enhancement factor is defined as the product of the column length reduction factor times the factor by which the carrier gas linear velocity increases in comparison with the conventional GC-MS parameters:

$$
\mathrm{SEF}=\frac{3000 \times V}{L \times 34}=88 \times \frac{V}{L}
$$

where $V$ is the fast GC carrier gas velocity in centimeters per second and $L$ is the column length in centimeters. The SEF actually constitutes the reduction factor in the flow time of the carrier gas through the column in comparison with conventional GC-MS. Clearly, the larger the SEF is, the faster the GC-MS analysis can be with a higher trade-off of GC resolution. We note, however, that the SEF does not necessarily directly reflect the exact reduction of the analysis time because this is affected also by the column temperature and its programming rate, especially where very short analysis periods are concerned. In relation to our definition of SEF, we advance here a subclassification of GC-MS in relation to the SEF: (1) Normal GC-MS is performed with SEF around 1; (2) fast GC-MS is performed with SEF in the range of 5-30 (about 10); (3) very fast GC-MS is defined with SEF in the range of 30-400 (about 100); (4) ultra-fast GC-MS is defined as a GC-MS with SEF in the range 400-4000 (about 1000).

In Figure 2 we show the fast, very fast, and ultra-fast GC-MS of different mixtures of the indicated under- 


\section{STEROIDS GC-SMB-EI-MS}
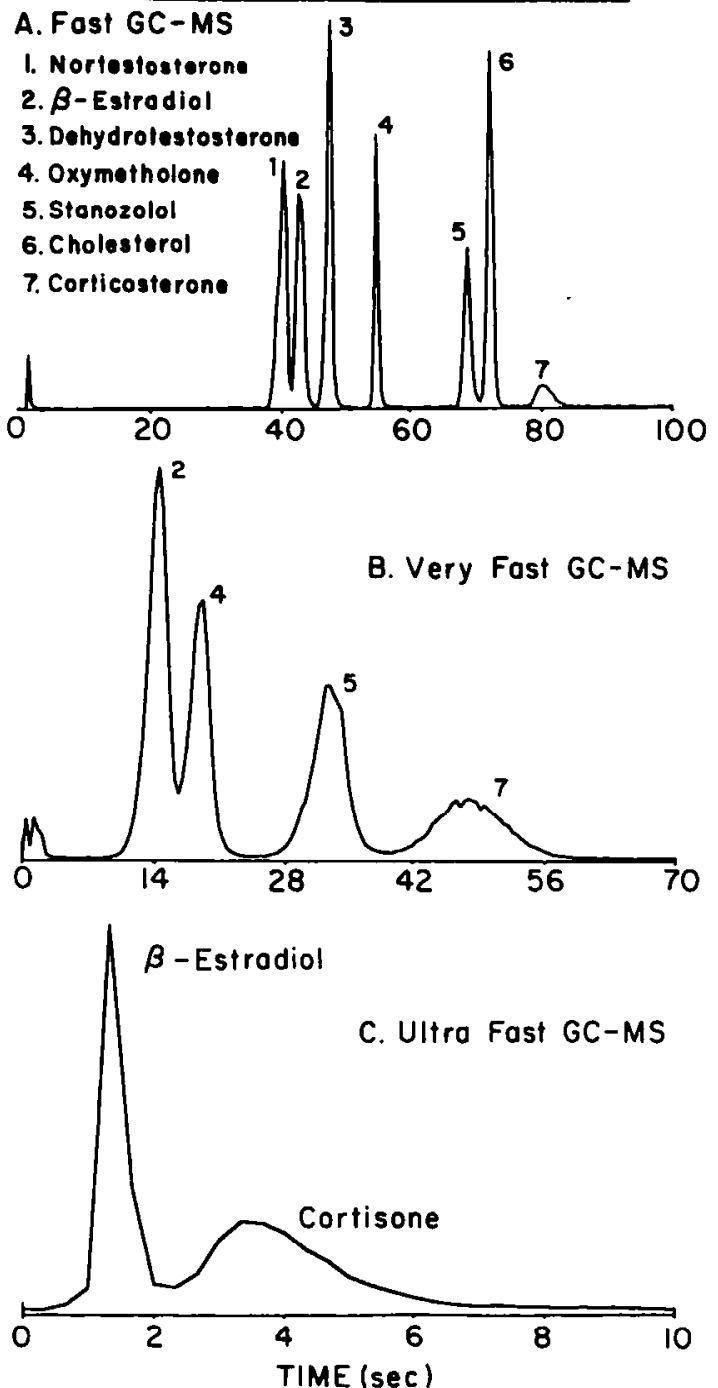

Figure 2. Fast, very fast, and ultra-fast GC-MS of the indicated steroids (different mixtures). Total ion count is presented versus time. (a) Thirty nanograms of each analyte were injected into a 4-m-long narrow bore column (250- $\mu \mathrm{m}$ i.d.). Temperature programming was applied $\left(200-250^{\circ} \mathrm{C}\right.$ with $30^{\circ} \mathrm{C} / \mathrm{min}$ rate) as well as flow programming. The split-splitless injector temperature was $2400^{\circ} \mathrm{C}$. (b) A 3-m-long megabore column was used and 400 ng of each compound were injected. The column temperature was ramped from $190-250^{\circ} \mathrm{C}$ at a rate of $50^{\circ} \mathrm{C} / \mathrm{min}$. The SPI injector temperature was $\sim 240{ }^{\circ} \mathrm{C}$. (c) The $50-\mathrm{cm}$ megabore column was employed with $100 \mathrm{ng}$ of each of the analytes. The column temperature was $235^{\circ} \mathrm{C}$, the injector temperature was $280{ }^{\circ} \mathrm{C}$, and the helium carrier gas velocity was estimated to be $500 \mathrm{~cm} / \mathrm{s}$.

ivatized steroids. The analysis was performed with 40 ng of each compound $( \pm 10 \%)$ and used $70-\mathrm{eV}$ electron ionization. Fast GC-MS was achieved with a $4-\mathrm{m}$ narrow bore column that had a flow rate of $2 \mathrm{~mL} / \mathrm{min}$, which resulted in a SEF of 15 . The very fast GC-MS was achieved with a $300-\mathrm{cm}$-long megabore column with a helium column flow rate of $60 \mathrm{~mL} / \mathrm{min}$, which resulted in a SEF of 135 . The ultra-fast GC-MS was achieved with a 50-cm-long megabore column with a column flow rate of about $80 \mathrm{~mL} / \mathrm{min}$, which resulted in a SEF of 1100 . With the fast GC-MS, (Figure 2a) the seven indicated steroids are fully chromatographically separated and the analysis is completed in about $90 \mathrm{~s}$. However, the large variation in the integrated peak area suggests that the majority of the corticosterone is dissociated and does not reach the mass spectrometer ion source. Stanozolol and oxymetholone also are partially dissociated. The thermolability property of corticosterone also manifested itself by poorer reproducibility of its relative peak area, which depends on the details of the experimental parameters. Dissociation in the injector may lead to new GC peaks at earlier retention times; however, molecular degradation on the column is a continuous process that is known to produce only a small and broad background, which is hard to observe, prior to the molecular elution time. In the very fast chromatogram (Figure $2 \mathrm{~b}$ ) we show that the peak areas of $\beta$-estradiol, oxymetholone, and stanozolol are similar, which serves as solid evidence for the practical elimination of their dissociation. Even corticosterone's relative integrated peak area is now over $50 \%$ of that of $\beta$-estradiol and its reproducibility is much better. When the ultra-fast GC-MS analysis of corticosterone was employed (not shown), no dissociation was observed and it could be quantitatively measured. The ultra-fast GC-MS in Figure $2 c$ shows the analysis of cortisone and $\beta$-estradiol. Among the steroids we have analyzed, cortisone was found to be the most thermally labile compound and could not be analyzed by fast GC-MS at all.

The slight peak tail of cortisone is due to an injector temperature that is too low. At higher injector temperatures, this peak tail was eliminated at the price of some reduction of the integrated peak area (which is about $60 \%$ of that of $\beta$-estradiol). In Figure 2, a clear trade-off is demonstrated between the speed enhancement factor and the ability to analyze thermally labile underivatized steroids. We also note that the very fast chromatogram was completed in under $1 \mathrm{~min}$, whereas the ultra-fast chromatogram lasted less than $8 \mathrm{~s}$. It is obvious that this increased ability to handle thermally labile compounds is achieved with reduced chromatographic resolution. However, with electron ionization in SMB, the obtained mass spectra practically always show a pronounced molecular ion and high mass peaks that allow molecular identification and quantification in many cases, even with chromatographically unresolved peaks.

\section{Experimental Parameters that Affect the GC-MS of Thermally Labile Compounds}

In the design and practice of the analysis of thermally labile compounds we have tested and evaluated the effect of all the experimental parameters involved. Our findings and conclusions follow. 
GC injector. The injector is the place where most of the dissociation can occur, especially if it is hotter than the column. Based on our study, the use of on-column injection (where the sample is directly injected onto the dimethyl silicon surface of the column) is much better than the use of a glass liner as in the split-splitless injector. This result is partially due to the more inert surface of the column and partially due to the faster flow rate in the narrower column. An increase of the carrier gas flow rate was also very important to minimize the dissociation both in the on-column and split-splitless injectors. When column temperature programming was applied, the injector was kept slightly above the initial temperature of the column. The use of injector temperature programming with the SPI injector was not necessary because, in our case, the latest compound to elute was the most thermally labile. However, in cases where the opposite is true, the use of injector temperature programming is a known way to minimize such injector dissociation.

Our ultra-fast injector was equipped with a homemade Vespel liner that exhibited very good behavior with thermally labile compounds, which suggests that Vespel, as a material for liners, is superior to glass even though its useful temperature range is limited $\left(\sim 320^{\circ} \mathrm{C}\right)$.

Injection syringe. We used three types of syringes: (1) SGE (Australia) model 034055 "plunger-in" 1- $\mu$ L syringe. This syringe performed poorly with thermally labile molecules due to its relatively large metal surface area. (2) A conventional Hamilton (Reno, Nevada) $701 \mathrm{~N} 10-\mu \mathrm{L}$ syringe was used with the Varian 3400 GC. Minor dissociation was suspected on its metal needle when injected into a heated injector. (3) A Hamilton $955-\mu \mathrm{L}$ syringe equipped with a fused silica needle was found to be the best choice for injection into the ultra-fast GC that has no septum. Clearly, the fused silica surface is more inert than the metal of conventional syringes.

Capillary column. On-column injection can be performed at an injector temperature close to that of the column and thus all injector-induced dissociation is eliminated. Under these conditions, the column is the place where most of the dissociation occurs. The column length and carrier gas flow rate are important parameters that enable control over the SEF, and by that means control over the handling capability of thermally labile compounds as discussed before. We chose columns with thin films to reduce the retention times and to enable operation at lower temperatures. Three megabore columns were used: (1) J \& W Scientific (Folsom, CA) with DB-1 film, 0.15- $\mu \mathrm{m}$ film thickness; (2) SGE with BPX5 film, $0.25-\mu \mathrm{m}$ film thickness; (3) SGE with HT5 film, $0.15-\mu \mathrm{m}$ film thickness. We observed no differences in the performance of these columns. We chose these columns, which are relatively nonpolar, to further reduce the operational tempera- ture. Some polar compounds exhibited chromatographic peak tailing that may be reduced by the use of columns that have higher polarity. The use of a megabore column with $0.53-\mathrm{mm}$ i.d. is preferable because it allows on-column injection that minimizes injectorrelated dissociation.

Transfer line. Clearly, the transfer line can be harmful to the analysis of thermally labile compounds. Because it is not a part of the GC oven, its temperature must be compatible with that required for the last eluting compound, and thus it can induce dissociation of the more volatile thermally labile compounds. In our ultra-fast GC-MS there was no transfer line because the GC was isothermal. When fast or very fast GC was employed, the Varian 3400 was connected to the nozzle via a $0.7-\mathrm{m}$ transfer line continued by the $0.5-\mathrm{m}$ ultra-fast GC that served here as an additional transfer line. Our major surprising finding was that a deactivated quartz capillary was a very poor transfer line because it strongly adsorbed and induced peak tailing and dissociation of the thermally labile compounds. Thus, we used an extension of the separation capillary as a transfer line. It is also desirable to increase the carrier gas flow rate to maximum in the hot transfer line to minimize the residence time of the molecules; this was done only in the final $50-\mathrm{cm}$ portion of the transfer line.

Temperature and flow programming. The use of temperature programming is desirable to obtain narrow chromatographic peak widths and to reduce the analysis time. The rate of temperature increase should be limited to avoid excessively high column temperatures that can promote dissociation. This limitation is severe with conventional GC-MS of thermally labile compounds and it also exists to a smaller extent with fast GC-MS, dependent on the degree of molecular thermolability. On the other hand, a temperature programming rate that is too low, combined with the high carrier gas velocities involved, resulted in broader GC peaks associated with reduced detection sensitivities. With very fast GC-MS, the upper limit of $50^{\circ} \mathrm{C} / \mathrm{min}$ can be used because the molecules elute in only a few seconds after the temperature of their mobility is reached. With the ultra-fast GC-MS, very fast temperature programming rates are desirable [23], but were unavailable to us; thus, column flow programming was used [4] as an effective alternative by closing valve $V_{2}$ (described in Figure 1) at some predetermined time after the start of the GC run.

Supersonic nozzle. Basically, the nozzle did not promote any noticeable dissociation because it had a minimal volume and maximum flow rate [24]. We found that it could even be held at $50^{\circ} \mathrm{C}$ below the column temperature. However, the analysis of thermally labile compounds resulted in some problems with nozzle 
clogging (up to about once every few days), which was the result of decomposition that formed particles that were carried away to the nozzle. The use of glass wool behind the nozzle alleviated the nozzle clogging problem, but because of suspected to promotion of dissociation (unproved), we decided to work without it. We worked with alumina and Vespel nozzles. The Vespel nozzle performed slightly better for vibrational cooling, but both nozzles could be used.

MS ion source. No dissociation or any other problem was observed with the EI ion source when operated with thermally labile compounds. This is a major advantage of SMB-MS.

We believe that our ultra-fast GC, when operated with on-column fused silica syringe injection, performed well and was close to the ultimate limits of GC-MS in its capability to handle thermally labile compounds. The coupling of an external GC can be further improved by reduction of the transfer line length or elimination thereof.

\section{Fast GC-MS Analysis of Carbamate Pesticides}

In Figure 3 we demonstrate the very fast and ultra-fast GC-MS of a mixture of aldicarb, propoxur, carbofuron, aldicarb sulfone, carbaryl, and linuron. All these pesticides are incompatible with standard GC-MS analysis $[13,14]$ and thus they require fast GC-MS $[2$, 3], particle beam LC-MS [13-15], electrospray LC-MS [25], or thermospray LC-MS [26] methods for analysis. It is clearly observed that with very fast GC-MS (Figure 3a) with a speed enhancement factor of 100 , all these compounds were successfully analyzed and a reasonable GC separation was obtained. Forty nanograms of each pesticide were injected, and clearly aldicarb, and especially aldicarb sulfone, were partially dissociated. The first GC peak is of methanol dimers, whereas the next four GC peaks are of pesticide decomposition products and impurities. (The solvent methanol forms clusters in the SMB that dissociate upon ionization to a protonated dimer at $m / z 65$, which is included in the mass scanning range.) From a study of the injector and column parameter effects on these peaks (including changing temperatures and flows), we concluded that three of the latter peaks are from impurities in the sample as purchased from AccuStandard (New Haven, CT), whereas the fourth peak at $\sim 22 \mathrm{~s}$ is due to injector or early column dissociation of aldicarb sulfone. In the lower trace (Figure $3 b$ ), we demonstrate the dissociation-free analysis of aldicarb and aldicarb sulfone in less than $5 \mathrm{~s}$. From the similar peak area of both compounds, we conclude that no dissociation occurred. The first peak again is attributed to methanol dimers at $\mathrm{m} / \mathrm{z} 65$ formed from the methanol solvent in the SMB. Although the GC resolution of the ultra-fast GC-MS is reduced, this reduction is compensated by the fact that no dissociation occurs in the ion source, and the spec-

\section{CARBAMATES GC-SMB-EI-MS}
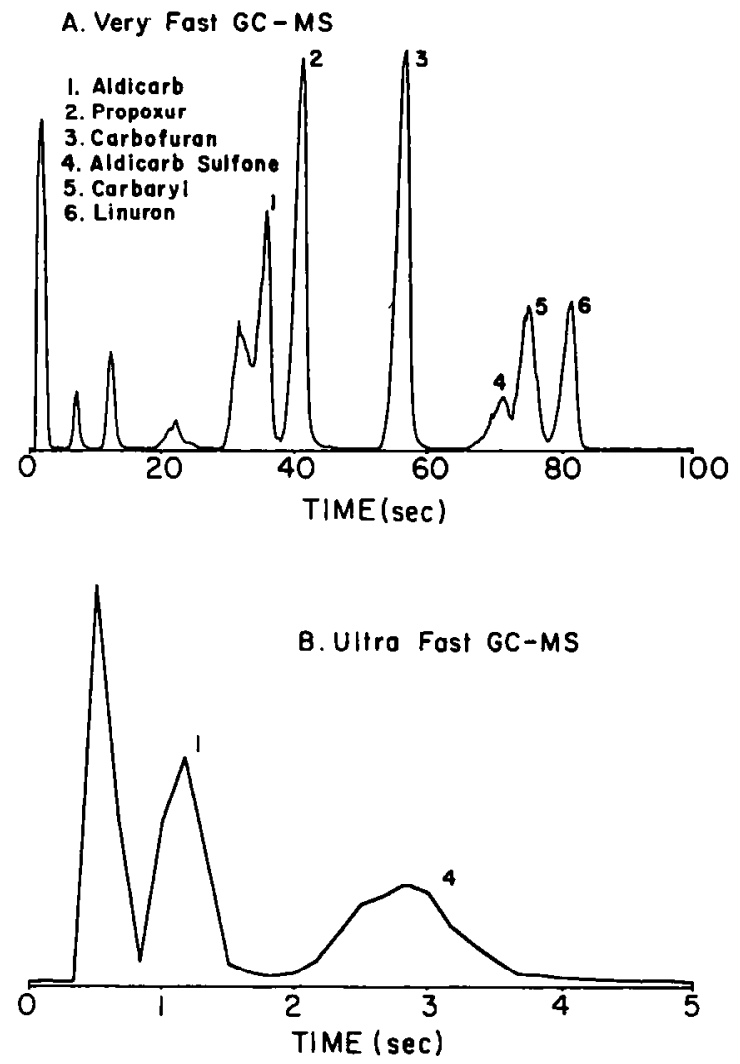

Figure 3. Very fast and ultra-fast GC-MS of the indicated carbamates (different mixtures). (a) Fifty nanograms of each compound were injected into a 3-m megabore column. The column temperature was programmed $\left(90-170^{\circ} \mathrm{C}\right.$ at a $50^{\circ} \mathrm{C} / \mathrm{min}$ rate) with a helium flow rate of about $40 \mathrm{~mL} / \mathrm{min}$. The injector temperature was $150^{\circ} \mathrm{C}$. (b) A $50-\mathrm{cm}$ megabore column held at $160^{\circ} \mathrm{C}$. The injector temperature was $160^{\circ} \mathrm{C}$. The amounts injected were $200 \mathrm{ng}$ of each analyte.

trum obtained is characterized by a considerable enhancement of the molecular ion and other high mass ions. In Figure 4, we show the same very fast GC-MS of the six carbamate mixture as in Figure $3 a$, but with an increased carrier gas flow rate of $200 \mathrm{~mL} / \mathrm{min}$. Under these conditions, the chromatographic resolution was reduced so that full separation and quantification were not possible. However, as shown, this problem was fully solved by reconstructed single-ion monitoring of the molecular ions of these compounds. The molecular ion peak is prominent in all these compounds except aldicarb sulfone, which was monitored through its $m / z 165$ peak. (The other peak at $m / z 165$ is a fragment of carbofuran.)

\section{Fast GC-MS of Pharmaceutical Compounds}

In Figure 5 we show the fast GC-MS of retinol, retinal, chlorpromazine, and quinine. These compounds were relatively easy to analyze on the scale of thermolability (they can be analyzed with low SEF), their mass spectra were very informative with pronounced molecular ions, and the analysis was completed in about $1 \mathrm{~min}$. 


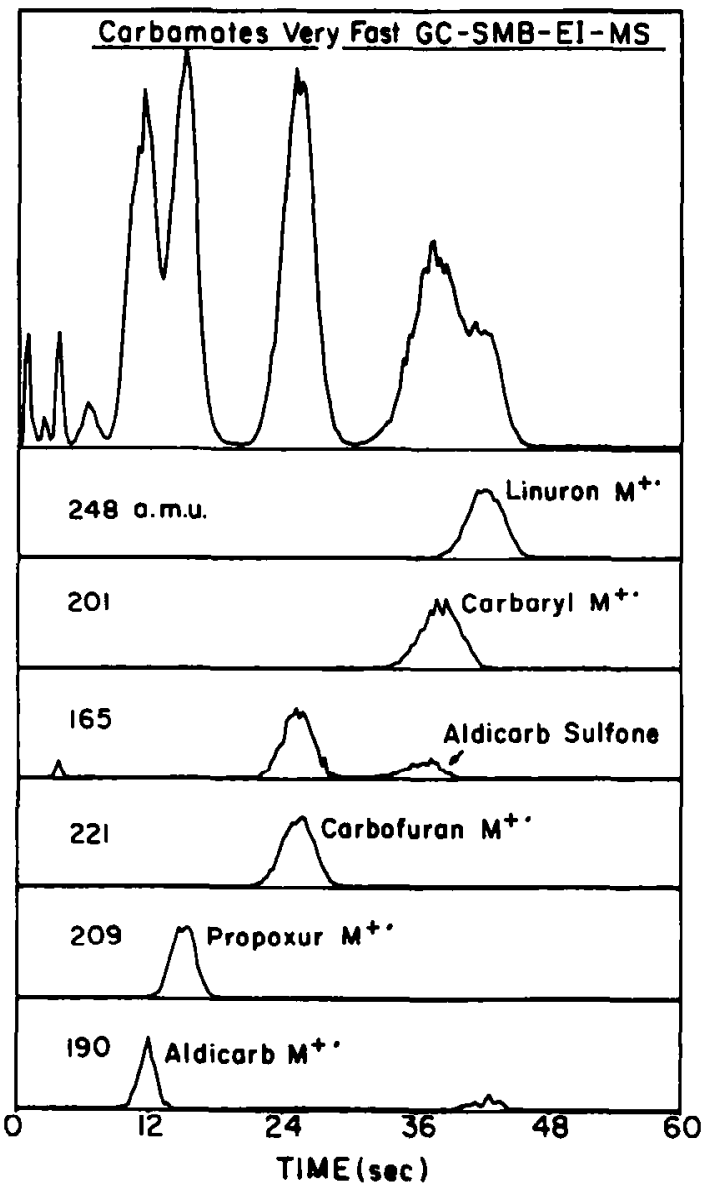

Figure 4. Quantitative identification of six carbamates through reconstructed single ion chromatograms of their molecular ion (or high mass fragment) peaks, obtained from an unresolved GC trace. The flow rate was about $200 \mathrm{~mL} / \mathrm{min}$ and the other conditions were similar to those in Figure 3a.

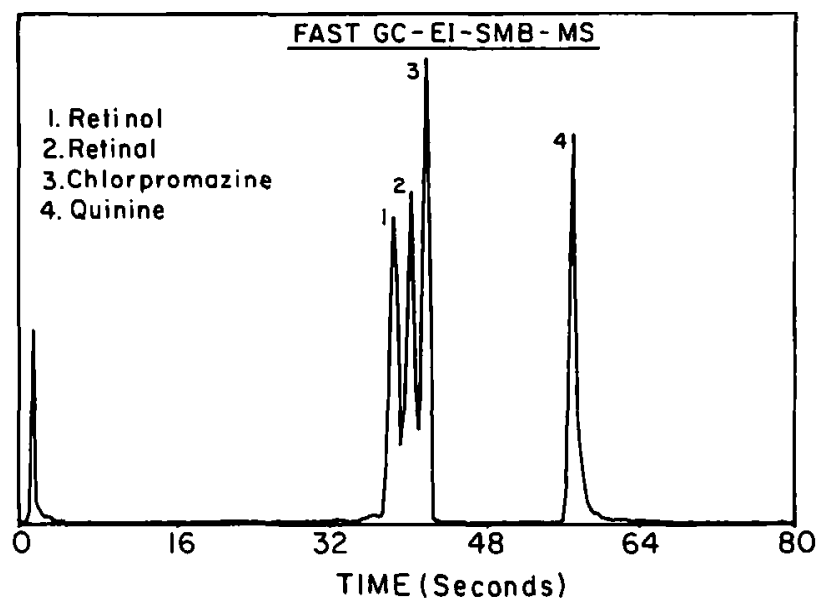

Figure 5. Fast GC-MS of the indicated compounds of pharmaceutical interest. Temperature programming $\left(150-300^{\circ} \mathrm{C}\right.$ at a rate of $50{ }^{\circ} \mathrm{C} / \mathrm{min}$ ) and flow programming were applied. The flow programming minimized quinine chromatographic peak tailing.
Quinine exhibited chromatographic peak tailing that was reduced with column flow programming.

The analysis of antibiotic drugs imposes severe limitations and these are the hardest to analyze due to their polarity (GC peak tailing problems), low volatility, and high thermolability. In Figure 6 we show the ultra-fast GC-MS trace of spectinomycin. Under these conditions (a SEF of 3000), this antibiotic drug could be analyzed and even quantified, although the GC separation was compromised. However, this ultra-fast GC provides the ability to quantify the drug through time integration of the peak. Note that antibiotics are not fully quantitatively analyzed even with particle beam LC-MS due to severe peak tailing in the ion source [12]. With electrospray LC-MS, improved analysis is achieved, but with limited sensitivity [27]. The observed mass spectrum shown in the lower part of Figure 6 is very rich with high mass informative peaks that include a pronounced molecular ion that enables quantification even in chromatographically unresolved peaks.

\section{Electron Impact Mass Spectra and their Library Searchability}

One of the most important aspects of GC-MS concerns the quality and level of information provided by the
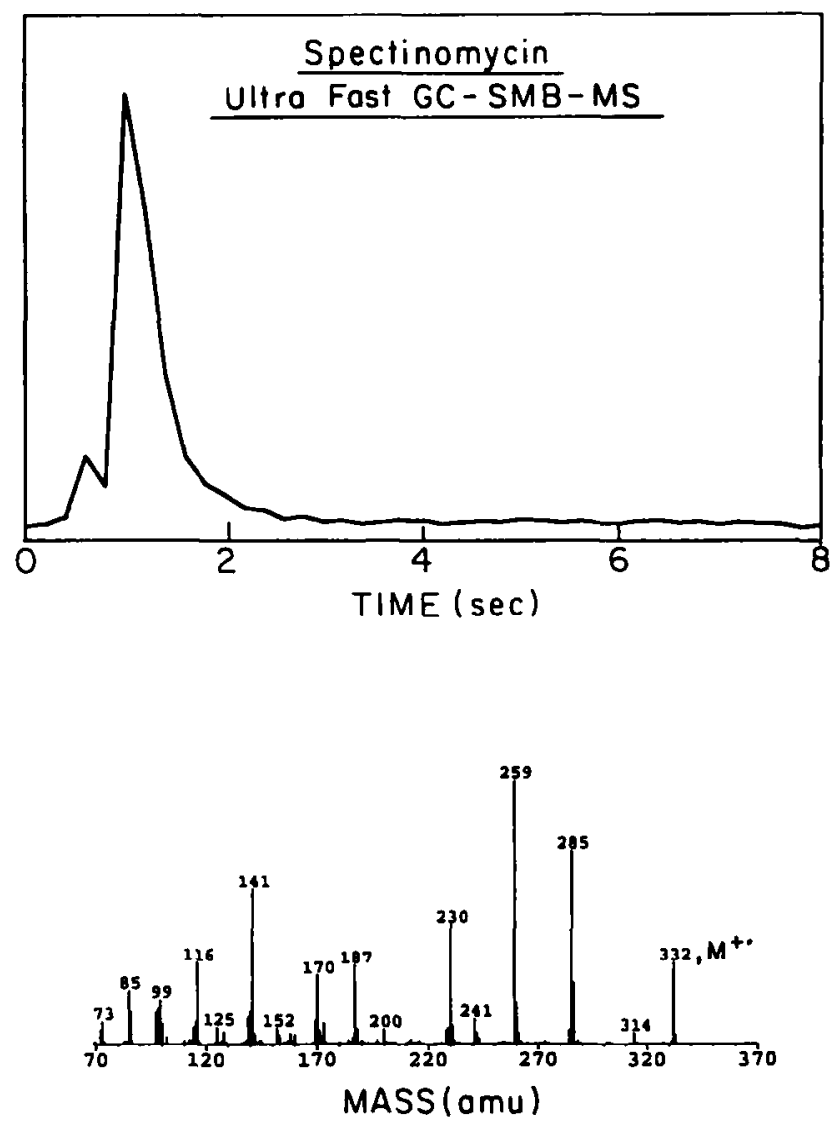

Figure 6. Ultra-fast GC-MS of spectinomycin. A 50-cm megabore column was held at $260^{\circ} \mathrm{C}$ while the GC trace was obtained, which resulted in the $70-\mathrm{eV}$ El mass spectrum shown in the lower panel. 
obtained mass spectra and their compatibility with the existing 70-eV electron impact libraries such as the NIST. This aspect is more important with thermally labile compounds whose integrity is in doubt, because they also can easily dissociate in the mass spectrometer ion source.

The ion source temperature is a major parameter that not only influences the dissociation of thermally labile compounds, but also governs the degree of molecular ion fragmentation. The ion source temperature effect on the EI mass spectra is well known and documented [15, 28-30]. In GC-MS instruments, the ion source is held at a compromised temperature value between two conflicting requirements. On the one hand, a high ion source temperature promotes molecular and molecular ion dissociation; on the other hand, at an insufficient ion source temperature, chromatographic peak tailing is observed, which reduces the GC resolution, sensitivity, and reproducibility. Standard ion source temperatures are around $200-250^{\circ} \mathrm{C}$. Similar ion source temperatures are used in particle beam LC-MS, which also relies on intra-ion source thermal vaporization and fast pumping out of the ion source.

In supersonic molecular beams, the sample molecules are vibrationally supercooled to below $-200{ }^{\circ} \mathrm{C}$, and at this temperature they contain a negligible amount of internal thermal energy. Under these conditions the electron energy is the only parameter that governs the degree of ion fragmentation [14, 31, 32], and the ion source temperature is irrelevant to the molecule and molecular ion dissociation, while the response time is always ultra-fast. This feature is achieved in a Brink-type open ion source design, which has the electron filament close to the ion cage, that is usually at a relatively high temperature. Most of the molecules are tranferred in a "fly-through" trajectory through the ion source, where molecules that scatter from the ion source walls and thermalize are filtered out after being ionized and are not observed. As a result, the electron ionization source exhibits a tail-free ultra-fast chromatographic response time, combined with electron ionization mass spectra of vibrationally cold molecules as if the ion source were at cryogenic temperatures. The 70-eV EI-MS in SMB are therefore characterized by an enhanced relative abundance of the molecular ion that is almost always observed, and to a smaller extent, other high mass peaks which are also more prnounced. This feature is very beneficial for molecular identification as shown in Figure 4.

One of the most important features of EI-MS is the extensive libraries available for identification and confirmation. At first sight it can be argued that the increased relative abundance of the molecular ion reduces the library searchability of spectra obtained by using SMB. However, we have found that the library compatibility with SMB is very good, and with thermally labile compounds it is even better than that exhibited with conventional GC-EI-MS or particle beam LC-MS. In Figure 7, we compare the 70-eV
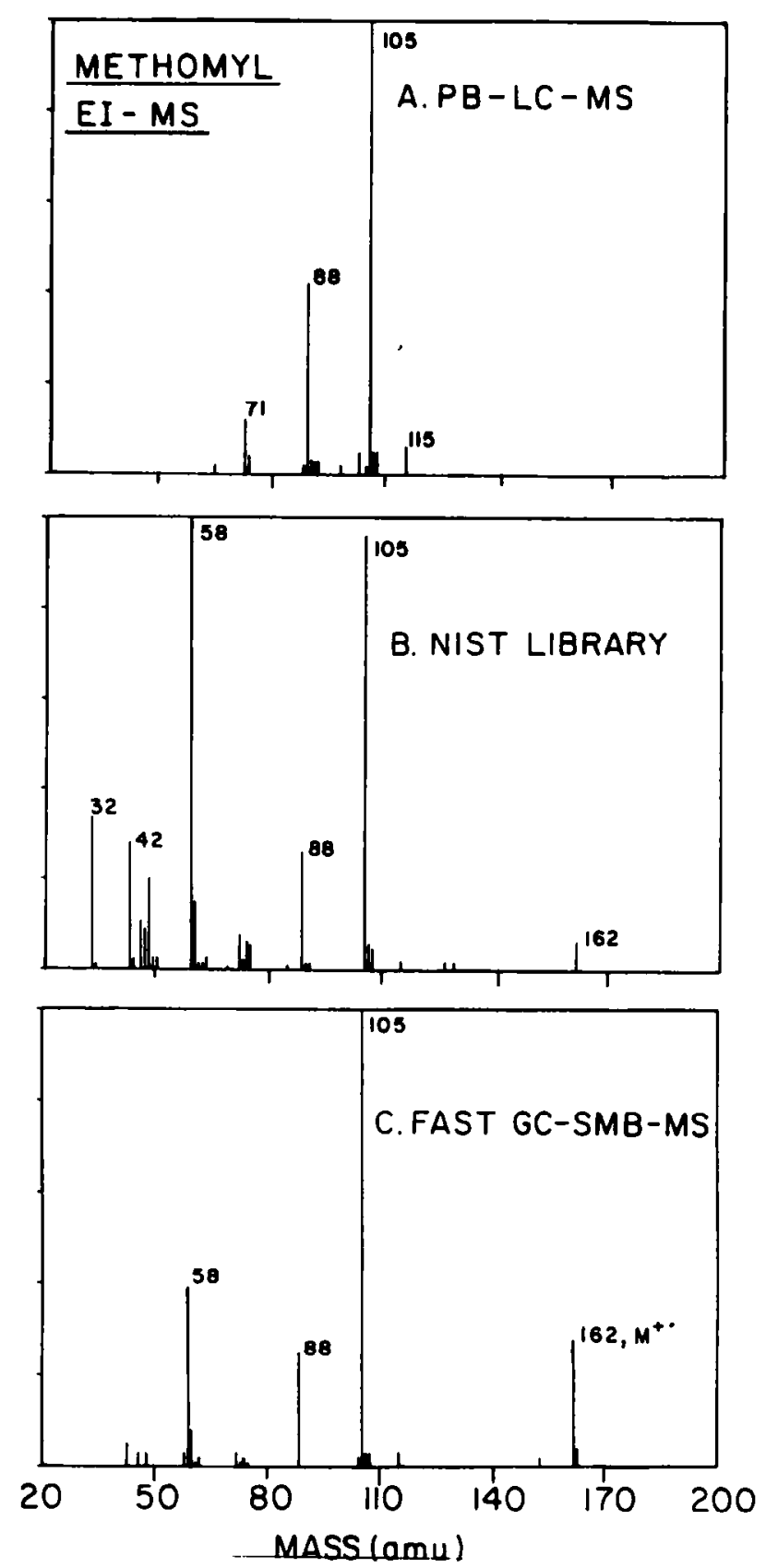

Figure 7. 70-eV electron ionization mass spectrum of methomyl (lannate), achieved (a) by particle beam LC-MS [13], (c) by fast GC-SMB-MS, and (b) as presented in the NIST library. The mass spectra shown were obtained with averaging across the GC peaks. The particle beam LC-MS mass spectrum was obtained by reprocessing the data of Budde et al. [13] and it shows all the reported major peaks, without the noise of peaks below $3 \%$ relative abundance.

EI-MS of methomyl, obtained with fast GC-MS in SMB (Figure 7c), with that of the NIST library (Figure $7 \mathrm{~b})$ and that obtained with particle beam LC-MS of Budde et al. [13] (Figure 7a). The enhanced molecular ion feature is clearly observed, together with a relative reduction of the low mass $\mathrm{m} / \mathrm{z} 58$ and 42 peaks. In spite of these differences, methomyl is the first choice in the library search and it appears far before the 
second alternative. In contrast, the EI-MS of methomyl obtained with particle beam LC-MS does not show any molecular weight peak [13]. Most probably, this difference is due to a higher electron ionization source temperature in the particle beam LC-MS instrument than that used to obtain the library EI-MS. Probably the library mass spectrum was obtained at a relatively low ion source temperature (such as $150{ }^{\circ} \mathrm{C}$ ) by using direct sample introduction to ensure the lack of dissociation as well as to reduce the molecular ion fragmentation for this thermally labile compound. Thus, as the $\mathrm{M}^{+\cdot}$ peak is lower in the library in comparison with that of the SMB, it is further reduced under the temperature required for the particle beam LC-MS. We suggest that the EI-MS in SMB shown in Figure 7 matches with the NIST library mass spectrum better than that obtained under particle beam LC-MS conditions, and the pronounced $\mathrm{M}^{+\cdot}$ peak better allows its identification in unresolved chromatography through selected ion monitoring (or reconstructed ion chromatograms). In Figure 8 we compare the 70-eV EI-MS in SMB of cytidine (Figure 8c), with that of the NIST library (Figure $8 \mathrm{~b}$ ) and that obtained with particle beam LC-MS [12] (Figure 8a). Clearly the mass spectrum in SMB is much closer to the mass spectrum of the NIST library than that of the particle beam LC-MS. Whereas cytidine is a highly thermally labile compound, it is reasonable to assume that although it had been chromatographically separated by the liquid chromatograph, it was fully dissociated under the harsh thermal conditions of the particle beam ion source and thus exhibited no high mass peaks. Again, the NIST mass spectrum probably was obtained at a lower ion source temperature by using direct sample introduction, and even then, only a minor $\mathrm{M}^{+\cdot}$ peak was shown. As before, with SMB-EI, the enhanced molecular ion was observed and our library search provided cytidine as the first choice. In Figure 9 we show 70-eV electron impact mass spectra obtained in SMB for aldicarb, propoxur, corticosterone, and cortisone. All these mass spectra include a molecular ion even though only the library spectrum of cortisone exhibits a significant $\mathrm{M}^{+\cdot}$ ion. In addition, other high mass fragments are observed and thus these mass spectra can be considered as high quality and informative mass spectra in addition to their library compatibility.

During this study of fast and very fast/ultra-fast GC-MS, we studied and obtained the $70-\mathrm{eV}$ EI-SMB-MS of 32 thermally labile compounds. The major peaks of these mass spectra, as well as comments on the GC requirements for their analysis are shown in Table 1 . Note that of these 32 molecules, 5 (antibiotics) do not have library spectra in the NIST library, and the library spectra of 5 other compounds do not exhibit molecular ions $(<0.1 \%)$. On the other hand, with fast GC-SMB-EI, we demonstrate a significant molecular ion ( $>5 \%$ ) for 29 of these molecules; the others are aldicarb-sulfone, which exhibits the new $m / z 165$ fragment peak, and cephapirin and cloxacillin,
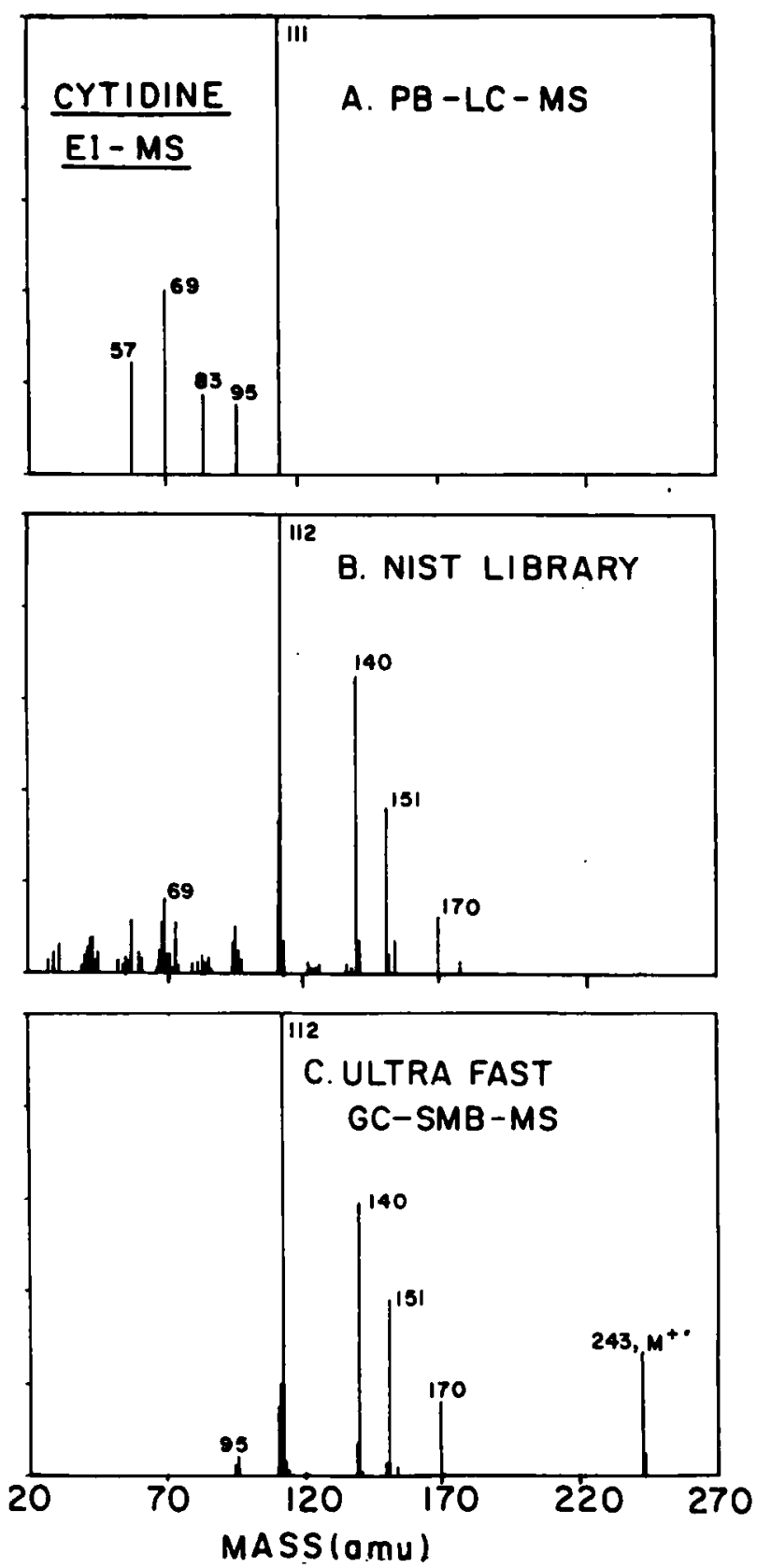

Figure 8. 70-eV electron ionization mass spectrum of cytidine, achieved (a) by particle beam LC-MS [12], (c) by fast GC-SMB-MS, and (b) as presented by the NIST library. The particle beam LC-MS mass spectrum was obtained by reprocessing the data of Voyksner et al. [12] from their Table 2.

which do not have NIST library spectra. The molecular ion is enhanced in most of the spectra. Note that these mass spectra were taken with our quadrupole mass analyzer (VG-SXP 600), which suffers from a significant reduction of ion transmission efficiency with mass, so that the real molecular ion enhancement is higher than is apparent. For some of the molecules (several steroids), where the $\mathrm{M}^{+\cdot}$ peak relative abundance is $100 \%$ even in the NIST library (as well as with SMB-EI), the ratio of this peak to high fragment ion peaks is higher with SMB-EI, which indicates less fragmentation. 


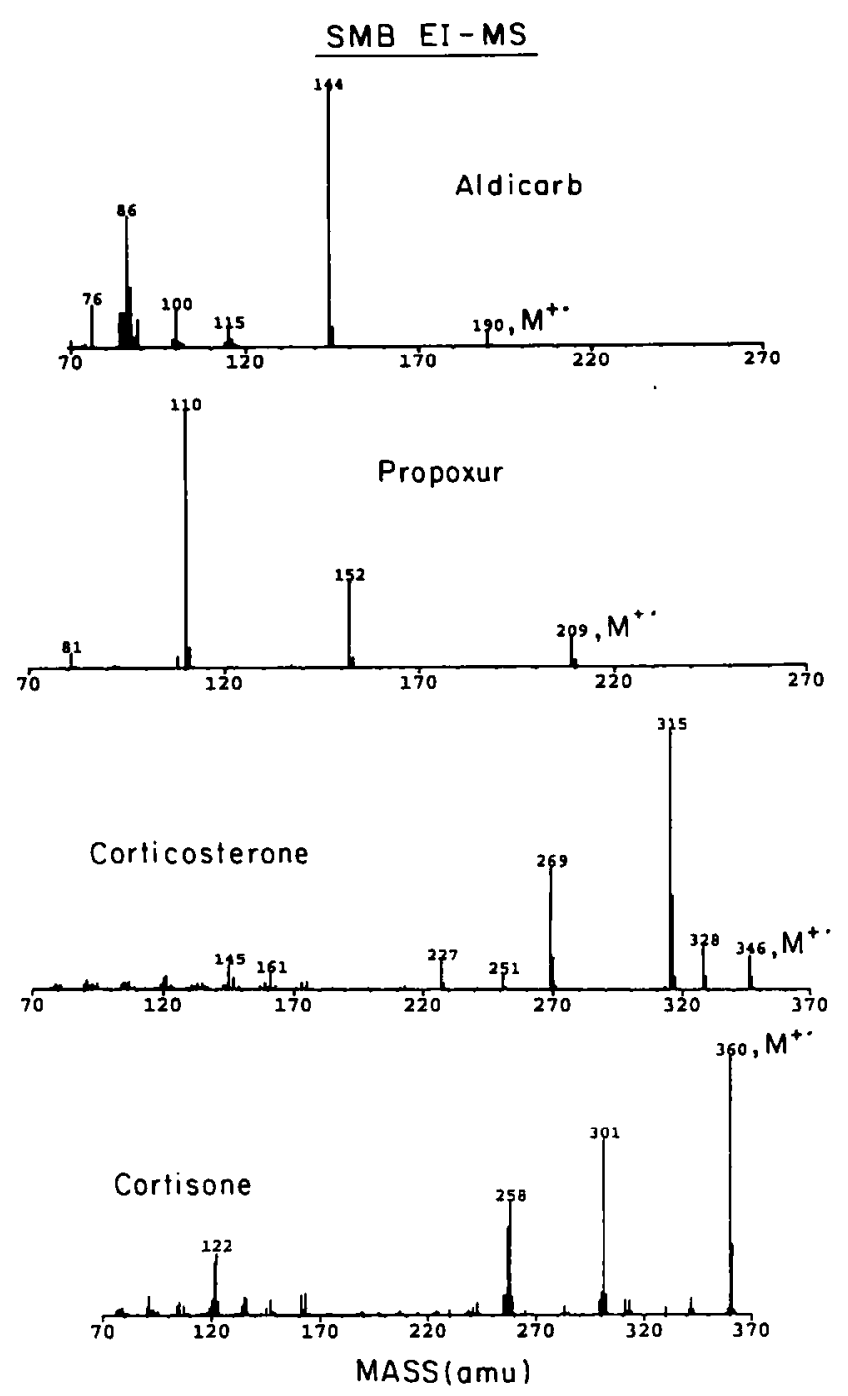

Figure 9. 70-eV electron ionization mass spectra of the indicated analytes achieved in supersonic molecular beams, reconstructed from the chromatograms shown in Figures 3 and 2.

The GC methods and column temperatures indicated in Table 1 represent conditions where a quantitative or almost quantitative GC response was achieved (except for some of the antibiotics, where it is indicated). Some GC difficulties (such as broadening and tailing) also are mentioned. Usually, the reproducibility with the better behaving compounds was better than $\pm 10 \%$. For those compounds with the remark "not fully quantitative," the reproducibility was within a factor of 2, mostly due to problems in the exact reproduction of the manual syringe insertion time and thus the degree of dissociation of some of the very polar and thermally labile antibiotics that partially dissociated in the ultra-fast GC injector and syringe.

\section{Analysis of $17 \beta$-Estradiol in Urine and Plasma Extracts}

The ultimate test of any new method is its applicability with real world examples. $17 \beta$-estradiol was chosen for the test because it is a widely used hormone (as the estrogen in the estrogen-progestin therapy of postmenopausal symptoms), whose analysis is required especially in human plasma and urine. In Figure 10 we demonstrate the fast GC-MS analysis of underivatized $17 \beta$-estradiol in human plasma and urine extracts. The extracts were obtained from the Isracl Biological Institute following extraction with chloroform, evaporation of the chloroform, and dilution in a smaller volume of toluene to a 10:1 ratio of extract concentration (the volume of toluene corresponds to $1 / 10$ of that of the biological fluid). $17 \beta$-estradiol was then spiked at a concentration level of $100 \mathrm{ppb}$ (to simulate a concentration of $10 \mathrm{ppb}$ in the original fluids while assuming $100 \%$ recovery by extraction) and $0.2 \mu \mathrm{L}$ was injected splitless into the ultra-fast GC-MS. In Figure 10 we show the ultra-fast GC-MS of $17 \beta$-estradiol achieved in under $6 \mathrm{~s}$ with single ion monitoring at the molecular ion of $m / z 272$. The major feature demonstrated in Figure 10 is the considerable selectivity of $70-\mathrm{eV}$ EI-MS in SMB. With the single ion monitoring trace obtained at $m / z 272$, the blank samples showed only a 20-40ppb background peak of an unknown compound at the elution time of $17 \beta$-estradiol. This time overlap of
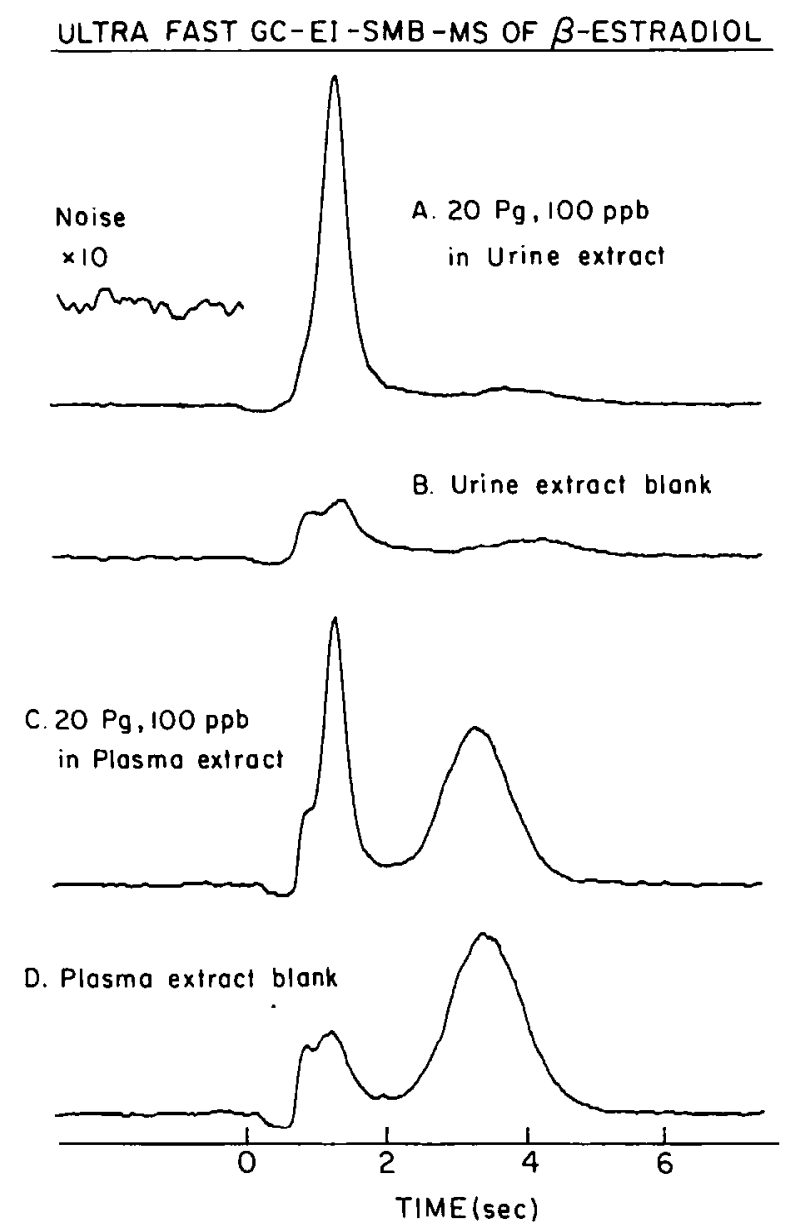

Figure 10. The ultra-fast GC-MS analysis of $17 \beta$-estradiol spiked at a 100-ppb level into 10:1 concentrated urine and plasma extracts. $0.2 \mu \mathrm{L}$ was injected at a column temperature of $190^{\circ} \mathrm{C}$. 
Table 1. 70-eV EI-SMB mass spectral data and GC conditions

\begin{tabular}{|c|c|c|c|c|c|c|c|}
\hline \multirow[b]{2}{*}{ Component } & \multirow[b]{2}{*}{ Mol. wt. } & \multicolumn{2}{|c|}{$\begin{array}{c}\text { Mass } \\
\text { spectrum }\end{array}$} & \multirow{2}{*}{$\begin{array}{l}\text { NIST }^{a} \\
\text { library } \\
\mathrm{M}^{+\cdot}(\%)\end{array}$} & \multirow{2}{*}{$\begin{array}{l}\text { GC method } \\
\text { required }\end{array}$} & \multirow{2}{*}{$\begin{array}{l}\text { Col. } \\
\text { temp } \\
\left({ }^{\circ} \mathrm{C}\right)\end{array}$} & \multirow[b]{2}{*}{ Comments } \\
\hline & & $m / z$ & $\%$ & & & & \\
\hline \multicolumn{8}{|c|}{ Pesticides (Carbamates) } \\
\hline \multirow[t]{6}{*}{ Aldicarb } & 190 & 190 & 5 & No $\mathrm{M}^{+\cdot}$ & Very fast & 140 & \\
\hline & & 144 & 100 & & & & \\
\hline & & 115 & 6 & & & & \\
\hline & & 100 & 13 & & & & \\
\hline & & 86 & 50 & & & & \\
\hline & & 76 & 15 & & & & \\
\hline \multirow[t]{4}{*}{ Aldicarb sulfone } & 222 & - & - & No $\mathrm{M}^{+}$ & Ultra fast, & 150 & \\
\hline & & 165 & 10 & & very fast & & \\
\hline & & 143 & 53 & & & & \\
\hline & & 86 & 100 & & & & \\
\hline \multirow[t]{5}{*}{ Carbaril } & 201 & 201 & 14 & 3 & Fast & 170 & \\
\hline & & 144 & 100 & & & & \\
\hline & & 127 & 1 & & . & & \\
\hline & & 115 & 26 & & & & \\
\hline & & 89 & 2 & & & & \\
\hline \multirow[t]{6}{*}{ Carbofuran } & 221 & 221 & 23 & 6 & Fast & 160 & \\
\hline & & 164 & 100 & & & & \\
\hline & & 149 & 32 & & & & \\
\hline & & 131 & 2 & & & & \\
\hline & & 123 & 2 & & & & \\
\hline & & 77 & 1 & & & & \\
\hline \multirow[t]{6}{*}{ Linuron } & 248 & 248 & 100 & 11 & Fast & 180 & \\
\hline & & 187 & 16 & & & & \\
\hline & & 160 & 55 & & & & \\
\hline & & 133 & 28 & & & & \\
\hline & & 124 & 25 & & & & \\
\hline & & 109 & 10 & & & & \\
\hline \multirow[t]{6}{*}{ Methiocarb } & 225 & 225 & 49 & 16 & Fast & 180 & \\
\hline & & 168 & 100 & & & & \\
\hline & & 153 & 48 & & & & \\
\hline & & 109 & 2 & & & & \\
\hline & & 91 & 2 & & & & \\
\hline & & 77 & 3 & & & & \\
\hline \multirow{3}{*}{$\begin{array}{l}\text { Methomyl } \\
\text { (lannate) }\end{array}$} & 162 & 162 & 62 & 6 & Very fast, & 140 & \\
\hline & & 105 & 100 & & fast & & \\
\hline & & 88 & 17 & & & & \\
\hline \multirow[t]{4}{*}{ Propoxur } & 209 & 209 & 12 & No $\mathrm{M}^{+}$ & Fast & 150 & \\
\hline & & 152 & 32 & & & & \\
\hline & & 110 & 100 & & & & \\
\hline & & 81 & 5 & & & & \\
\hline \multirow[t]{3}{*}{ Rotenone } & 394 & 394 & 15 & 23 & Very fast & 220 & GC broadened \\
\hline & & 192 & 100 & & & & peak \\
\hline & & 177 & 7 & & & & \\
\hline \multirow[t]{4}{*}{ Siduron } & 232 & 232 & 20 & 5 & Fast & 200 & \\
\hline & & 135 & 3 & & & & \\
\hline & & 119 & 5 & & & & \\
\hline & & 93 & 100 & & & & \\
\hline
\end{tabular}


Table 1. 70-eV EI-SMB mass spectral data and GC conditions (continued)

\begin{tabular}{|c|c|c|c|c|c|c|c|}
\hline \multirow[b]{2}{*}{ Component } & \multirow[b]{2}{*}{ Mol. wt. } & \multicolumn{2}{|c|}{$\begin{array}{c}\text { Mass } \\
\text { spectrum }\end{array}$} & \multirow{2}{*}{$\begin{array}{c}\text { NIST }^{a} \\
\text { library } \\
\mathrm{M}^{+\cdot}(\%)\end{array}$} & \multirow{2}{*}{$\begin{array}{l}\text { GC method } \\
\text { réquired }\end{array}$} & \multirow{2}{*}{$\begin{array}{l}\text { Col. } \\
\text { temp } \\
\left({ }^{\circ} \mathrm{C}\right)\end{array}$} & \multirow[b]{2}{*}{ Comments } \\
\hline & & $m / 2$ & $\%$ & & & & \\
\hline \multicolumn{8}{|c|}{ Steroids } \\
\hline \multirow[t]{5}{*}{$17 \beta$-Estradiol } & 272 & 272 & 100 & 100 & Fast & 200 & \\
\hline & & 213 & 20 & & & & \\
\hline & & 172 & 13 & & & & \\
\hline & & 160 & 13 & & & & \\
\hline & & 146 & 10 & & & , & \\
\hline \multirow[t]{7}{*}{ Cholesterol } & 386 & 386 & 63 & 100 & Fast & 240 & \\
\hline & & 368 & 20 & & & & \\
\hline & & 353 & 15 & & & & \\
\hline & & 301 & 73 & & & & \\
\hline & & 275 & 100 & & & & \\
\hline & & 213 & 57 & & & & \\
\hline & & 145 & 47 & & & & \\
\hline \multirow[t]{6}{*}{ Corticosterone } & 346 & 346 & 12 & 2 & Very fast & 250 & \\
\hline & & 328 & 17 & & & & \\
\hline & & 315 & 100 & & & & \\
\hline & & 269 & 48 & & & & \\
\hline & & 227 & 11 & & & & \\
\hline & & 145 & 9 & & & & \\
\hline \multirow[t]{7}{*}{ Cortisone } & 360 & 360 & 100 & 100 & Ultra fast & 250 & \\
\hline & & 342 & 6 & & & & \\
\hline & & 330 & 2 & & & & \\
\hline & & 313 & 6 & & & & \\
\hline & & 301 & 68 & & & & \\
\hline & & 258 & 43 & & & & \\
\hline & & 122 & 22 & & & & \\
\hline$\Delta^{1}$-Dehydro- & 286 & 286 & 14 & 45 & Fast & 220 & \\
\hline \multirow[t]{2}{*}{ testosterone } & & 147 & 8 & & & & \\
\hline & & 122 & 100 & & & & \\
\hline \multirow[t]{5}{*}{ 19-Nortestosterone } & 274 & 274 & 100 & 100 & Fast & 200 & \\
\hline & & 256 & 13 & & & & \\
\hline & & 231 & 8 & & & & \\
\hline & & 215 & 12 & & & & \\
\hline & & 110 & 35 & & & & \\
\hline \multirow[t]{5}{*}{ Oxymetholone } & 332 & 332 & 100 & 25 & Very fast. & 230 & \\
\hline & & 314 & 9 & & fast & & \\
\hline & & 275 & 45 & & & & \\
\hline & & 216 & 22 & & & & \\
\hline & & 174 & 32 & & & & \\
\hline \multirow[t]{6}{*}{ Progesterone } & 314 & 314 & 100 & 70 & Fast & 220 & \\
\hline & & 299 & 9 & & & & \\
\hline & & 272 & 75 & & & & \\
\hline & & 229 & 71 & & & & \\
\hline & & 191 & 32 & & & & \\
\hline & & 124 & 44 & & ${ }^{\circ}$ & & \\
\hline \multirow{5}{*}{ Stanozolol } & 328 & 328 & 100 & 60 & Very fast, & 240 & \\
\hline & & $\begin{array}{l}313 \\
295\end{array}$ & $\begin{array}{l}5 \\
5\end{array}$ & & tast & & \\
\hline & & 270 & 54 & & & & \\
\hline & & 257 & 45 & & & & \\
\hline & & 96 & 35 & & & & \\
\hline
\end{tabular}


Table 1. 70-eV EI-SMB mass spectral data and GC conditions (continued)

\begin{tabular}{|c|c|c|c|c|c|c|c|}
\hline \multirow[b]{2}{*}{ Component } & \multirow[b]{2}{*}{ Mol. wt. } & \multicolumn{2}{|c|}{$\begin{array}{c}\text { Mass } \\
\text { spectrum }\end{array}$} & \multirow{2}{*}{$\begin{array}{c}\text { NIST }^{a} \\
\text { library } \\
\mathrm{M}^{+\cdot}(\%)\end{array}$} & \multirow{2}{*}{$\begin{array}{l}\text { GC method } \\
\text { required }\end{array}$} & \multirow{2}{*}{$\begin{array}{l}\text { Col. } \\
\text { temp } \\
\left({ }^{\circ} \mathrm{C}\right)\end{array}$} & \multirow[b]{2}{*}{ Comments } \\
\hline & & $m / z$ & $\overline{\%}$ & & & & \\
\hline \multicolumn{8}{|c|}{ Pharmaceuticals } \\
\hline \multirow[t]{6}{*}{ Ampicillin } & 349 & 349 & 10 & No data & Ultra fast & 330 & Not fully \\
\hline & & 303 & 15 & & & & quantitative \\
\hline & & 271 & 10 & & & & \\
\hline & & 232 & 45 & & & & \\
\hline & & 160 & 80 & & & & \\
\hline & & 106 & 100 & & & & \\
\hline \multirow[t]{5}{*}{ Cephapirin } & 423 & - & - & No data & Ultra fast & 280 & Not fully \\
\hline & & 351 & 30 & & & & quantitative \\
\hline & & 168 & 30 & & & & $\cdot$ \\
\hline & & 125 & 100 & & & & \\
\hline & & 111 & 80 & & & & \\
\hline \multirow[t]{4}{*}{ Chlortetracycline } & 478 & 478 & 100 & 23 & Ultra fast & 300 & Not fully \\
\hline & & 460 & 40 & & & & quantitative \\
\hline & & 435 & 80 & & & & \\
\hline & & 418 & 20 & & & & \\
\hline \multirow[t]{7}{*}{ Cloxacillin } & 435 & - & - & No data & Ultra fast & 280 & Not fully \\
\hline & & 389 & 15 & & & & quantitative \\
\hline & & 273 & 100 & & & & . \\
\hline & & 213 & 30 & & & & \\
\hline & & 178 & 40 & & & & \\
\hline & & 160 & 30 & & & & \\
\hline & & 137 & 30 & & & & \\
\hline \multirow[t]{5}{*}{ Cytidine } & 243 & 243 & 40 & No $M^{+}$ & Ultra fast & 330 & Severe GC peak \\
\hline & & 170 & 22 & & & & tailing \\
\hline & & 151 & 50 & & & & \\
\hline & & 140 & 70 & & & & \\
\hline & & 112 & 100 & & & & \\
\hline \multirow[t]{4}{*}{ Furosemide } & 330 & 330 & 100 & 9 & Ultra fast & 300 & Not fully \\
\hline & & 250 & 30 & & & & quantitative \\
\hline & & 232 & 20 & & & & \\
\hline & & 81 & 60 & & & & \\
\hline \multirow[t]{7}{*}{ Methylene blue } & 285 & 285 & 100 & No data & Fast & 250 & \\
\hline & & 270 & 50 & & & & \\
\hline & & 255 & 5 & & & & \\
\hline & & 241 & 3 & & & & \\
\hline & & 225 & 5 & & & & \\
\hline & & 142 & 6 & & & & \\
\hline & & 101 & 4 & & & & \\
\hline \multirow[t]{8}{*}{ Spectinomycin } & 332 & 332 & 35 & No data & Ultra fast & 260 & \\
\hline & & 314 & 4 & & & & \\
\hline & & 285 & 84 & & & & \\
\hline & & 259 & 100 & & & & \\
\hline & & 230 & 60 & & & & \\
\hline & & 187 & 53 & & & & \\
\hline & & 170 & 46 & & & & \\
\hline & & 141 & 80 & & & & \\
\hline
\end{tabular}


Table 1. 70-eV EI-SMB mass spectral data and GC conditions (continued)

\begin{tabular}{|c|c|c|c|c|c|c|c|}
\hline \multirow[b]{2}{*}{ Component } & \multirow[b]{2}{*}{ Mol. wt. } & \multicolumn{2}{|c|}{$\begin{array}{c}\text { Mass } \\
\text { spectrum }\end{array}$} & \multirow{2}{*}{$\begin{array}{l}\text { NIST } \\
\text { library } \\
\mathrm{M}^{+\cdot}(\%)\end{array}$} & \multirow{2}{*}{$\begin{array}{l}\text { GC method } \\
\text { required }\end{array}$} & \multirow{2}{*}{$\begin{array}{l}\text { Col. } \\
\text { temp } \\
\left({ }^{\circ} \mathrm{C}\right)\end{array}$} & \multirow[b]{2}{*}{ Comments } \\
\hline & & $\overline{m / z}$ & $\%$ & & & & \\
\hline \multicolumn{8}{|c|}{ Pharmaceuticals } \\
\hline \multirow[t]{9}{*}{ Tetracycline } & 444 & 444 & 15 & 22 & Ultra fast & 260 & Not fully \\
\hline & & 426 & 40 & & & & quantitative \\
\hline & & 384 & 60 & & & & \\
\hline & & 313 & 20 & & & & \\
\hline & & 268 & 20 & & & , & \\
\hline & & 256 & 90 & & & & \\
\hline & & 170 & 30 & & & & \\
\hline & & 127 & 100 & & & & \\
\hline & & 84 & 60 & & & & \\
\hline \multirow[t]{5}{*}{ Thiamine } & 264 & 264 & 15 & 2 & Ultra fast & 270 & \\
\hline & & 233 & 2 & & & & \\
\hline & & 143 & 100 & & & & \\
\hline & & 112 & 80 & & & & \\
\hline & & 85 & 15 & & & & \\
\hline \multirow{5}{*}{ Chlorpromazine } & 318 & 318 & 100 & 25 & Fast & 200 & \\
\hline & & 272 & 45 & & & & \\
\hline & & 232 & 82 & & & & \\
\hline & & 86 & 43 & & & & \\
\hline & & 58 & 18 & & & & \\
\hline \multirow[t]{5}{*}{ Quinine } & 324 & 324 & 6 & No $\mathrm{M}^{+\cdot}$ & Fast & 250 & GC peak tailing \\
\hline & & 189 & 3 & & & & \\
\hline & & 172 & 2 & & & & \\
\hline & & 158 & 3 & & & & \\
\hline & & 136 & 100 & & & & \\
\hline \multirow[t]{5}{*}{ Retinal } & 284 & 284 & 100 & 100 & Fast & 220 & \\
\hline & & 269 & 9 & & & & \\
\hline & & 255 & 5 & & & & \\
\hline & & 173 & 24 & & & & \\
\hline & & 161 & 21 & & & & \\
\hline \multirow[t]{7}{*}{ Retinol } & 286 & 286 & 86 & 60 & Fast & 220 & \\
\hline & & 268 & 100 & & & & \\
\hline & & 255 & 94 & & & & \\
\hline & & 185 & 35 & & & & \\
\hline & & 173 & 29 & & & & \\
\hline & & 159 & 39 & & & & \\
\hline & & 119 & 28 & & & & \\
\hline
\end{tabular}

"Data taken from the NIST mass spectral search program, version 4.5, 1994.

the background peak is presumably due to the reduced GC resolution of the ultra-fast GC and was the sensitivity limiting factor. We note that this low detection limit is achieved with the very complex matrices of urine and plasma extracts, even with the limited separation capability of the ultra-fast GC-MS. Clearly, better separation can be achieved with the fast or very fast GC-MS that can be used with $17 \beta$-estradiol as shown in Figure 2. However, in Figure 10 we preferred to demonstrate the detection of $17 \beta$-estradiol under the limited injection volume and reduced chromatographic resolution of the ultra-fast GC-MS, because this method can be shared with the widest range of thermally labile compounds.
We believe that the major feature of prominent molecular ions of EI-MS in SMB is of importance in enabling the analysis shown in Figure 10, not only for $17 \beta$-estradiol, but also for a large variety of molecules. However, the foregoing results suggest that further work is required to establish an analysis method based on SMB-MS.

\section{Use of SMB versus Other Methods of Fast GC-MS}

We have shown and discussed the analysis of thermally labile steroids, carbamates, and drugs by using fast GC-MS, based on sampling with ionization in supersonic molecular beams. The use of supersonic 
molecular beams for sampling and ionization is relatively new and has several advantages in comparison with other fast GC-MS methods in the analysis of thermally labile compounds:

1. SMB allows faster GC-MS analysis with speed enhancement factors up to 2 orders of magnitude higher than other methods of fast GC-MS. The very high possible SEF of up to 3000 is the result of the very high column flow rate acceptable by the supersonic nozzle of up to $240 \mathrm{~mL} / \mathrm{min}$. Thus SMB-MS can provide the ultimate capability of handling thermally labile compounds.

2. The analysis time can be ultra-fast (as little as a few seconds) with a full freedom of choice of trade-offs between the analysis time, GC resolution, and the amount of intracolumn dissociation allowed, where no constraints exist on the column diameter and length.

3. Larger sized splitless samples can be injected (up to $100 \mu \mathrm{L}$ [4]) due to the very high column flow rate. As a result, lower minimum detected concentration can be achieved within a given analysis time constraint.

4. SMB-MS provides higher quality electron impact mass spectra, which are characterized by enhanced molecular ions and library searchable fragmentation patterns.

5. No ion source-related peak tailing is exhibited regardless of the sample volatility.

6. The fast GC-MS in SMB is also compatible with hyperthermal surface ionization, which is a tunable selective and ultra sensitive ionization method $[4,17]$.

7. The modest number of separation plates available with fast GC-MS in SMB is compatible with the limited scan speed of quadrupole mass analyzers and does not require time-of-flight mass analysis. The lost GC resolution is compensated for by the extra selectivity of EI in SMB achieved through the enhanced molecular ion that is the most selective peak for the identification of target compounds in complex mixtures, as demonstrated in Figure 10.

8. The merits of SMB such as high temperature tail-free operation, informative EI mass spectra, increased sensitivity with hyperthermal surface ionization, and so forth, also can be implemented with conventional GC-MS by using 30-m narrow bore columns. In fact, we used the Varian 3400 GC with two columns installed simultaneously in two separate injectors. Thus conventional GC-MS and fast or very fast GC-MS can be switched back and forth simply through the injector used: no hardware change is required.

In conclusion, we believe SMB-MS enables a unique fast GC-MS to be obtained that can provide the ultimate handling capability of thermally labile com- pounds and full freedom in the trade-off of this capability with other experimental parameters.

\section{Fast GC-MS in SMB-Comparison with Particle Beam LC-MS}

It is interesting to compare the fast GC-MS in SMB with particle beam LC-MS, because both methods incorporate the thermal vaporization of the sample molecules.

1. We estimate that the fast GC-MS in SMB is softer and induces less dissociation than particle beam LC-MS. It involves a few hundred thermal adsorption-desorption cycles (assumed from the observed number of separation plates) from the highly inert dimethyl silicon GC column surface and uses lower temperatures than the stainless steel electron impact ion source surfaces. Thus, the fast CC-MS in SMB is at least equivalent to particle beam LC-MS in its ability to handle thermally labile compounds without dissociation and to obtain meaningful combined separation and mass spectra.

2. In particle beam LC-MS, dissociation at the ion source degrades the quality of the mass spectra but still allows total ion current LC peaks to be obtained (as long as peak tailing problems do not exist). In fast GC-MS, dissociation in the column or injector eliminates our ability to introduce the sample to the ion source. Thus, particle beam LC-MS can handle compounds that are more thermally labile, but may produce low quality mass spectra. For many of these compounds no library mass spectra are available.

3. The chromatographic resolution is comparable because the number of separation plates of fast GC-MS is equivalent to that of $L C$, whereas very fast and ultra-fast GC-MS exhibit lower separation capability. When relatively nonvolatile and polar compounds are analyzed, ion source-related peak tailing is observed with the particle beam LC-MS $[12,33$, 34]. With fast GC-MS, no such peak tailing occurs [4], but with highly polar compounds, GC columnrelated tailing appears.

4. For molecules that may be analyzed by both methods, the fast GC-MS in SMB provides higher quality mass spectra and is faster and more sensitive.

5. Both methods, when operated properly, provide library searchable electron impact mass spectra.

Thus, in our opinion, fast GC-MS in SMB can provide an alternative method for the analysis of compounds that are now analyzed by particle beam LC-MS. However, fast GC-MS has its limits, and it cannot analyze highly thermally labile compounds, which may be analyzed only by thermospray or electrospray LC-MS. On the other hand, the same fast GC-MS system also can be used without any changes 
for conventional GC-MS with several unique advantages.

\section{Acknowledgments}

This work was partially supported by grants from the German-Israeli Foundation for Scientific Research and Development and the James Franck Institute for Laser Matter Interactions.

\section{References}

1. Rossi, S. A.; Johnson, J. V.; Yost, R. A. Biol. Mass Spectrom. 1992, 21, 420-430.

2. Trehy, M. L.; Yost, R. A.; Dorsey, J. G. Anal. Chem. 1986, 58, 14-19.

3. Trehy, M. L.; Yost, R. A.; McCreary, J. J. Anal. Chem. 1984, 56, 1281-1285.

4. Dagan, S.; Amirav, A. Int. J. Mass Spectrom. Ion Processes 1994, 133, 187-210.

5. Henneberg, D.; Henrichs, U.; Schomburg, G. I. Chromatogr. 1975, 112, 343-352.

6. Cramers, C. A.; Scherpenzeel, G. J.; Leclercq, P. A. J. Chromatogr. 1981, 203, 207-216.

7. Hail, M. E.; Yost, R. A. Anal. Chem. 1989, 61, 2402-2410.

8. Wollnik, H.; Becker, R.; Götz, H.; Kroft, A.; Jung, H.; Chen, C. C.; Van Ysacker, P. G.; Janssen, H. G.; Snijders, H. M. J.; Leclercq, P. A.; Cramers, C. A. J. Mass Spectrom. Ion Processes 1994, 130, L7-L11.

9. Holland, J. F.; Enke, C. G.; Allison, J.; Stults, J. T.; Pinkston, J. D.; Newcome, B.; Watson, J. T. Anal. Chem. 1983, 55, 997A-1010A.

10. Willoughby, R. C.; Browners, R. F. Anal. Chem. 1984, 56, 2626-2631.

11. Winkler, P. C.; Perkins, D. D.; Williams, W. K.; Browner, R. F. Anal. Chem. 1988, 60, 489-493.

12. Voyksner, R. D.; Smith, C. S.; Knox, P. Biomed. Environ. Mass Spectrom. 1990, 19, 523-534.
13. Budde, W. L.; Behymer, T. D.; Bellar, T. A.; Ho, J. S. J. Am. Water Works Assoc. 1990, 82, 60-65.

14. Behymer, T. D.; Bellar, T. A.; Budde, W. L. Anal. Chem. 1990 62, 1686-1690.

15. Betowski, L. D.; Pace, C. M.; Roby, M. R. J. Am. Soc. Mass Spectrom. 1992, 3, 823-830.

16. Kleintop, B. L.; Eades, D. M.; Yost, R. A. Anal. Chem. 1993, 65 , 1295-1300.

17. Amirav, A. Org. Mass Spectrom. 1991, 26, 1-17.

18. Brink, G. O. Rev. Sci. Instrum. 1966, 37, 857-860, 1626.

19. Persky, A.; Greene, E. F.; Kuppermann, A. J. Chem. Phys. 1968, 49, 2347-2357.

20. Amirav, A.; Danon, A. Mass Spectrometer Method and Apparatus for Analyzing Materials; U.S. Patent 5055677; 1991. Israel and European patent applications accepted.

21. Amirav, A.; Danon, A. Int. J. Mass Spectrom. Ion Processes 1990, 97, 107-113.

22. Danon, A.; Amirav, A. J. Phys. Chem. 1989, 93, 5549-5562.

23. Hail, M. E.; Yost, R. A. Anal. Chem. 1989, 61, 2410-2416.

24. Danon, A.; Amirav, A. Rev. Sci. Instrum. 1987, 58, 1724-1726.

25. Keenan, G. A. Proceedings of the 13th International Mass Spectrometry Conference; Budapest, 1994; p. 290.

26. Volmer, D,; Levsen, K. J. Am. Soc. Mass Spectrom. 1994, 5, 655-675.

27. Straub, R. F.; Voyksner, R. D. J. Chromatogr. 1993, 647, 167-181.

28. Chupka, W. A. J. Chem. Phys. 1971, 54, 1936-1947.

29. Genuit, W.; Nibbering, N. M. M. Int. I. Mass Spectrom. Ion Processes 1986, 73, 61.

30. Maccoll, A. Org. Mass Spectrom. 1986, 21, 601-611.

31. Dagan, S.; Amirav, A. J. Am. Soc. Mass Spectrom. 1995, 6, 120-131.

32. Amirav, A. J. Phys. Chem. 1990, 94, 5200-5202.

33. Tirke, A. P.; van der Hoven, R. A. M.; Niessen, W. M. A.; Fjaden, U. R.; van der Greef, J. J. Chromatogr. 1991, 554, 119-124.

34. Cappiello, A.; Famiglini, G. Anal. Chem. 1995, 67, 412-419. 